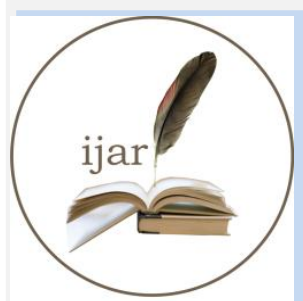

ISSN NO. 2320-5407
Journal Homepage: $-\underline{w w}$.journalijar.com
INTERNATIONAL JOURNAL OF
ADVANCED RESEARCH (IJAR)

Article DOI: $10.21474 / \mathrm{IJAR01/1368}$

DOI URL: http://dx.doi.org/10.21474/IJAR01/1368
INTERNATIONAL JOURNAL OF ADVANCED RESEARCH (JSAR)

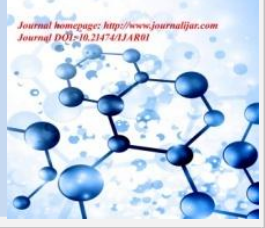

RESEARCH ARTICLE

\title{
MULTIFLAX CRACKERS FOR TYPE 2 DIABETIC PATIENTS- A MODIFIED FOOD PRODUCT.
}

\begin{abstract}
Akhila Vaidyanathan and Rupali Sengupta.
Department of Clinical Nutrition and Dietetics, Dr. BMN College of Home Science 338, R.A Kidwai road, Matunga, Mumbai.400019.
\end{abstract}

\section{Manuscript Info}

Manuscript History

Received: 12 June 2016

Final Accepted: 19 July 2016

Published: August 2016

Key words:-

Multiflax crackers, Thattai, Type 2

Diabetes, Flaxseeds, Modified,

Traditional.

\begin{abstract}
Multiflax crackers are developed as a snack for type 2 diabetic patients. The crackers are a healthy modification of traditional South Indian snack 'Thattai'. The modified food product attempts to improve fiber and the carbohydrate source used are such which are beneficial in lowering blood glucose levels such as jowar, whole wheat flour and ragi. The product is low in fat as they are baked compared to traditional product which is fried. Functional foods such as flaxseeds, sesame seeds, garlic are also used in this recipe. 5 point ranking scale was used for evaluation and a standardized product was developed.
\end{abstract}

Copy Right, IJAR, 2016,. All rights reserved.

\section{Introduction:-}

Diabetes as defined by (WHO, 2014) is a chronic disease, which occurs when the pancreas does not produce enough insulin, or when the body cannot effectively use the insulin it produces. This leads to an increased concentration of glucose in the blood. According to the Diabetes Atlas 2006 published by the International Diabetes Federation, the number of people with diabetes in India is currently around 40 million and this number is expected to rise to 70 million by 2025.According to (IDF diabetes atlas - 7th edition, 2015) 1 in 11 adults have diabetes (415 million), $46.5 \%$ of adults with diabetes are undiagnosed and by 2040, 1 adult in 10 (642 million) will have diabetes.

The product was planned under the Applied Food Science and Product Modification practical in the year 2015-2016. Multiflax crackers are a modification of traditional South Indian recipe 'Thattai' which are deep fried crispy savory snack made out of rice flour. The modified crackers are made out of whole wheat flour, jowar flour, ragi flour. Functional foods such as flaxseeds, sesame seeds and garlic are added to make it healthier for a diabetic patient. The crackers were baked unlike the traditional 'Thattai' which are fried. Therefore, these are low in fat and nutritious for a diabetic patient.

\section{Methodology:-}

Developing the food product:-

* The rice flour in the traditional recipe was replaced by whole wheat flour, jowar flour and ragi flour.

* Garlic which acts as a functional food, chili powder, curry leaves and coriander leaves were added to enhance flavor.

* The amount of oil was according to the requirement for baking the product as compared to traditional product in which deep frying method is used. Butter was not used in modified recipe. 
* The modified product also contain flaxseeds which is a functional food, it contains high level of essential omega 3 fatty acid i.e. Alfa Lipoic Acid (ALA), along with protein, fiber and plant compound called lignans that act as an antioxidant when ingested.

* It also contain white sesame seeds, a functional food, an excellent source of copper and a very good source of manganese, also a good source of calcium, magnesium, iron, phosphorus, vitamin B1, zinc, molybdenum, selenium, and dietary fiber.

Table 1:- Ingredients of Traditional and Modified recipes

\begin{tabular}{|r|r|r|r|}
\hline \multicolumn{1}{|l|}{ Thattai } & & & Multiflax crackers \\
\hline Rice flour & $25 \mathrm{~g}$ & Wheat flour & $15 \mathrm{~g}$ \\
\hline Fried gram flour & $5 \mathrm{~g}$ & Jowar flour & $10 \mathrm{~g}$ \\
\hline Bengal gram dal & $5 \mathrm{~g}$ & Ragi flour & $1 \mathrm{~g}$ \\
\hline Red chili powder & $5 \mathrm{~g}$ & White sesame seeds \\
\hline Unsalted butter & $5 \mathrm{~g}$ & Flaxseeds & 1 tbsp \\
\hline Oil & For deep frying & Green/red chili & 2 small \\
\hline Hing & A pinch & Coriander leaves \\
\hline Salt & to taste & Curry leaves & 1 spring \\
\hline & & Garlic & $3-4$ cloves \\
\hline & & Oil & $10 \mathrm{~g}$ \\
\hline & & Salt & to taste \\
\hline
\end{tabular}

Table 2:- Standardization of the developed food product

\begin{tabular}{|r|r|}
\hline INGREGRIENTS & AMOUNTS \\
\hline Wheat flour & $15 \mathrm{~g}$ \\
\hline Jowar flour & $10 \mathrm{~g}$ \\
\hline Ragi flour & $5 \mathrm{~g}$ \\
\hline White sesame seeds & $15 \mathrm{~g}$ \\
\hline Flaxseeds & $15 \mathrm{~g}$ \\
\hline Green/red chili & $2 \mathrm{small}$ \\
\hline Coriander leaves & 2 spring \\
\hline Curry leaves & 1 spring \\
\hline Garlic & 3 small cloves \\
\hline Oil & $10 \mathrm{~g}$ \\
\hline Salt & to taste \\
\hline
\end{tabular}

Figure 1:- Method of preparation

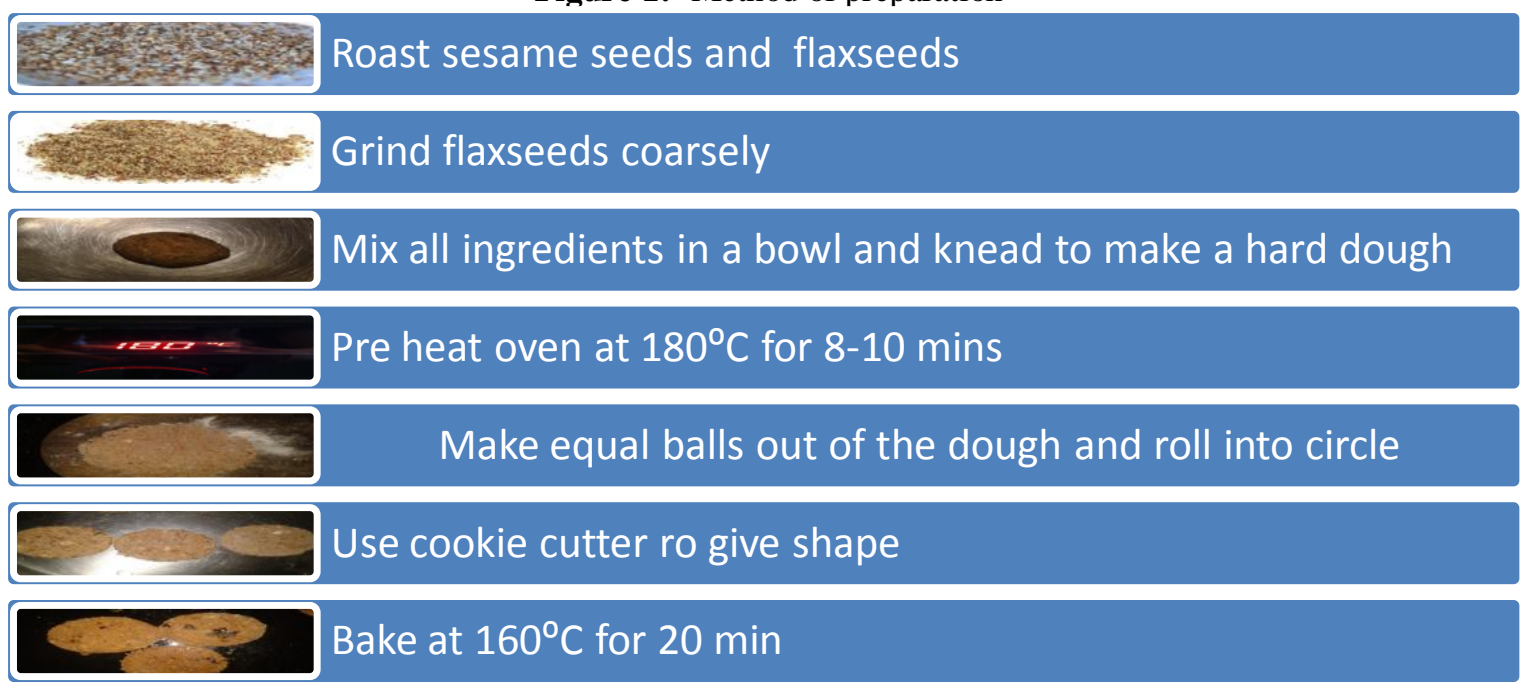


Table 3:- Comparison of nutritive value between traditional product 'Thattai' and modified product 'Multiflax Crackers'

Calculation of product was done with reference to Nutritive Value of Indian Foods and comparision was done between traditional and modified product. (C.Gopalan, 2012).

\begin{tabular}{|l|l|l|l|}
\hline Nutrient & Unit & Traditional product & Modified product \\
\hline Energy & $\mathrm{kcal}$ & 432 & 389 \\
\hline Protein & $\mathrm{gm}$ & 4.4 & 8.7 \\
\hline Carbohydrate & $\mathrm{gm}$ & 23.8 & 27.5 \\
\hline Fat & $\mathrm{gm}$ & 35.5 & 24.9 \\
\hline TDF & $\mathrm{gm}$ & 2.4 & 9.7 \\
\hline
\end{tabular}

Evaluation of the standardized product:-

Multiflax crackers were subjected to sensory evaluation based on 5 point ranking scale for appearance, concept, texture, taste, presentation using 35 panel members (30 naive panel members and 5 expert panel members). The score were based on the criteria: 5-excellent, 4-very good, 3-good, 2-satisfactory, 1-poor. There was a gradual improvement in the product week after week. In the last week all the panels rated the product as "excellent".

Figure 2:- Sensory evaluation

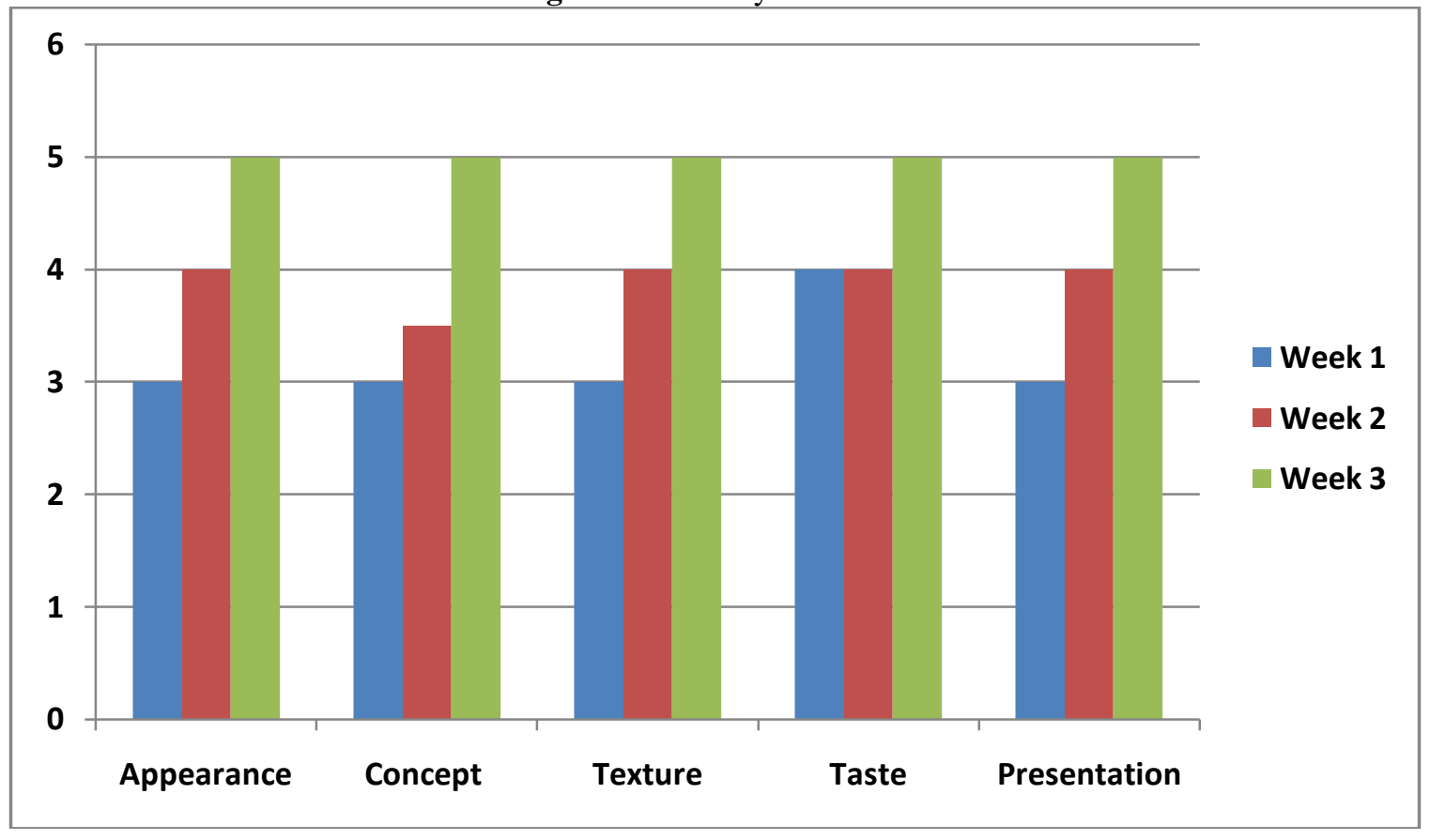

\section{Result:-}

The modified product contains fewer calories compared to traditional product. It is low in fat as it is baked compared to traditional product which is deep fried. The source of carbohydrate in the product helps in controlling blood sugar level in diabetic patient compared to traditional product. The fiber comparison of the product is better in comparison with the traditional product.

\section{Discussion:-}

The product contains 3 different types of flours such as whole wheat flour, jowar flour, ragi flour which are healthier option as compared to refined flour. Wheat flour is rich in dietary fiber, selenium, phosphorous, manganese, magnesium, calcium, zinc, copper, folate. Jowar is a very good source of B-vitamins like thiamin and riboflavin. It is also rich in phytochemicals including tannins, phenolic acids and anthocyanins. Ragi is extremely good source of iron, proteins and essential amino acids such as Valine, Methionine, Isoleucine, Threonine and Tryptophan. It contains essential nutrients like iron, calcium, potassium, and phosphorous. Has high content of proteins. 
A study was conducted on glycemic response to wheat flour. The blood glucose response to feeding 50-g carbohydrate portions of white and wholemeal bread and white spaghetti was studied in a group of nine diabetic subjects. Blood glucose rise after consumption of white and wholemeal bread were identical, but the response after spaghetti was markedly reduced. These results emphasize that food form rather than fiber may be important in determining the glycemic response and that pasta may be a useful source of carbohydrate in the diabetic diet. (Jenkins, 1983)

Another study by (McKeown NM, 2004) state that people who eat three or more servings of whole grains a day, especially from high-fiber cereals have less likelihood to develop insulin resistance and the metabolic syndrome, common precursors of both T2DM and CHD. Rave and Roggen investigated the potential of a whole-grain based dietary product (WG) in comparison to a nutrient-dense meal replacement product (MR) in a randomized two-way cross-over study. The comparison between both groups revealed that fasting serum insulin $(\mathrm{P}=0.031)$ and HOMA insulin resistance score $(\mathrm{P}=0.049)$ improved better with WG than with MR. It was concluded that WG favorably influences metabolic risk factors (like insulin resistance) for T2DM independent from the amount of body weight lost during a hypo-energetic diet. (Rave K, 2007).

A team of German researchers followed over 16,000 adults for a period of seven years and found that those who ate cereal fiber the most (relative risk for extreme quintiles, 0.72 [95\% confidence interval, 0.56-0.93]), had a 27\% lower risk of developing T2DM than those who ate the least. Components of whole grains, including magnesium, fiber, vitamin E, phytic acids, lectins, and phenolic compounds, are believed to contribute to risk reduction of T2DM as well as lowering blood glucose and blood insulin levels. In studies that examined the source of fiber, researchers found that fiber from whole grains, but not from fruit or vegetable sources, appears to exert the protective effect in reducing risk for developing T2DM.

A review of randomized control trials, in diabetic subjects showed that low GI diets compared to high GI diets lowered protein markers of glycemic control measured as $\mathrm{HbAlc}$ decreased by $0.5 \%$ (95\% CI -0.8 to -0.2 ; $\mathrm{P}<$ 0.001 ). This $0.5 \%$ reduction is clinically significant, as it corresponds to a lower dosage of medications for newly diagnosed patients (Sievenpiper JL, 2009) and the UK Prospective Diabetes Study (UKPDS) suggests that a 1\% reduction in mean $\mathrm{HbAlc}$ levels corresponds to a $21 \%$ reduction in risk for deaths related to diabetes and its complications (Rury R Holman, 1995). A recent epidemiological study among urban adults has shown that higher refined grain consumption is associated with dyslipidemia (low HDL and high TG), metabolic syndrome, and increased risk for type 2 diabetes.

The product also contain flaxseeds which contains high level of essential omega 3 fatty acid i.e. Alfa Lipoic Acid (ALA), along with protein, fiber and plant compound called lignans that act as an antioxidant when ingested. In this recipe flaxseeds has been added in ground form and grinding flaxseeds makes the inner compounds more accessible. Lignans present in flaxseeds are known to improve the blood sugar level in type 2 diabetes, having flaxseeds on a daily basis can help maintain blood sugar levels over an extended period of time.

The effects of ingestion of flaxseed gum on blood glucose and cholesterol, particularly low-density lipoprotein cholesterol, in type 2 diabetes were evaluated. Flaxseed gum was incorporated in wheat flour chapattis. Sixty patients of type 2 diabetes were fed a daily diet for 3 months, along with six wheat flour chapattis containing flaxseed gum $(5 \mathrm{~g})$, as per the recommendations of the American Diabetic Association. The control group (60 individuals) consumed an identical diet but the chapattis were without gum. Results showed a decrease in lowdensity lipoprotein cholesterol from $110 \pm 8 \mathrm{mg} / \mathrm{dl}$ to $92 \pm 9 \mathrm{mg} / \mathrm{dl}(\mathrm{P}=0.02)$. The study demonstrated the efficacy of flax gum in the blood biochemistry profiles of type 2 diabetes. (Goutam Thakur, 2009).

In a randomized, cross-over study overweight or obese men and postmenopausal women $(\mathrm{n}=25)$ with pre-diabetes consumed 0,13 , or $26 \mathrm{~g}$ ground flaxseed for 12 weeks. At the end of the study it was concluded that flaxseed intake decreased glucose and insulin and improved insulin sensitivity as part of a habitual diet in overweight or obese individuals with pre-diabetes. (Andrea M. Hutchins, 2013)

The product also contain white sesame seeds an excellent source of copper and a very good source of manganese, they are also a good source of calcium, magnesium, iron, phosphorus, vitamin B1, zinc, molybdenum, selenium, and dietary fiber. In addition to these important nutrients, sesame seeds contain two unique substances: sesame and sesamolin. Both of these substances belong to a group of special beneficial fibers called lignans, and have been 
shown to have a cholesterol-lowering effect in humans, and to prevent high blood pressure and increase vitamin $\mathrm{E}$ supplies in animals. Sesame has also been found to protect the liver from oxidative damage.

In an open label trial with two intervention periods comprised 22 male and 18 female patients, 45-65 years old, with mild to moderate hypertension and diabetes. Sesame oil was supplied to the patients, who were instructed to use it in place of other cooking oils for 45 days. Blood pressure (BP), anthropometric measurements, plasma glucose, glycated hemoglobin (HbA1c), lipid profiles [total cholesterol, low-density lipoprotein cholesterol (LDL-C), and high-density lipoprotein cholesterol, and triglycerides (TG)], lipid peroxidation [thiobarbituric acid-reactive substances (TBARS)], electrolytes (sodium, potassium, and chloride), and enzymic (superoxide dismutase, glutathione peroxidase, and catalase) and nonenzymic (vitamin $\mathrm{C}$, vitamin $\mathrm{E}, \beta$-carotene, and reduced glutathione) antioxidants were measured at baseline and after 45 days of sesame oil substitution. The same patients were then switched over to other oils like palm or groundnut oils as their regular oils at random for another 45 days, and the investigations were carried out again at the end. The results indicated that substitution of sesame oil as the sole edible oil has an additive effect in further lowering BP and plasma glucose in hypertensive diabetics (D. Sankar, 2006).

In another open label study included sixty type 2 diabetes mellitus patients divided into 3 groups, receiving sesame oil $(n=18), 5 \mathrm{mg} /$ day (single dose) of glibenclamide $(n=20)$, or their combination $(n=22)$. The patients were supplied with sesame oil except glibenclamide group, and instructed to use approximately $35 \mathrm{~g}$ of oil/day/person for cooking, or salad preparation for 60 days. $12 \mathrm{~h}$-fasting venous blood samples were collected at baseline ( 0 day) and after 60 days of the experiment for various biochemical analysis. The results showed that sesame oil exhibited synergistic effect with glibenclamide and can provide a safe and effective option for the drug combination that may be very useful in clinical practice for the effective improvement of hyperglycemia (Devarajan Sankar, 2010).

\section{Reference:-}

1. Andrea M. Hutchins, B. D. (2013). Daily flaxseed consumption improves glycemic control in obese men and women with pre-diabetes: a randomized study. Nutrition research, 367-375.

2. C.Gopalan, R. S. (2012). Nutritive value of Indian Foods. Hydrabad: National Instititute Of Nutrition (NINICMR).

3. D. Sankar, M. R. (2006). A Pilot Study of Open Label Sesame Oil in Hypertensive Diabetics. Journal of Medicinal Food, 408-412.

4. Devarajan Sankar, A. A. (2010). Sesame oil exhibits synergistic effect with anti-diabetic medication in patientswith type 2 diabetes mellitus. Clinical nutrition, 351-358.

5. Goutam Thakur, K. P. (2009). Effect of flaxseed gum on reduction of blood glucose and cholesterol in type 2 diabetic patients. International Journal of Food Sciences and Nutrition, 126-136.

6. IDF diabetes atlas - 7th edition. (2015). Retrieved from International Diabetes Federation: http://www.diabetesatlas.org/

7. Jenkins, T. M. (1983). Glycemic Response to Wheat Products: Reduced Response to Pasta but No Effect of Fiber. Diabetes care , 155-159.

8. McKeown NM, M. J. (2004). Carbohydrate nutrition, insulin resistance, and the prevalence of the metabolic syndrome in the Framingham Offspring Cohort. Diabetes care , 538-546.

9. Rave K, R. K. (2007). Improvement of insulin resistance after diet with a whole-grain based dietary product: results of a randomized, controlled cross-over study in obese subjects with elevated fasting blood glucose. The British Journal of nutrition, 929-936.

10. Rury R Holman, e. a. (1995). United Kingdom prospective diabetes study (UKPDS) 13: relative efficacy of randomly allocated diet, sulphonylurea, insulin, or metformin in patients with newly diagnosed non-insulin dependent diabetes followed for three years. The BMJ .

11. Sievenpiper JL, e. (2009). Effect of non-oil-seed pulses on glycaemic control: a systematic review and metaanalysis of randomised controlled experimental trials in people with and without diabetes. Diabetologia , 147995.

12. WHO. (2014). Retrieved from http://www.who.int/topics/diabetes_mellitus/en/ 